\title{
Polish Society of Allergology statement on the diagnosis and treatment of severe, difficult-to-control bronchial asthma
}

\author{
Maciej Kupczyk ${ }^{1}$, Zbigniew Bartuzi², Anna Bodzenta-Łukaszyk ${ }^{3}$, Marek Kulus ${ }^{4}$, Piotr Kuna ${ }^{1}$, Izabela Kupryś-Lipińska ${ }^{1}$, \\ Henryk Mazurek ${ }^{5}$
}

\begin{abstract}
${ }^{1}$ Clinic of Internal Diseases, Asthma and Allergies, N. Barlicki University Clinical Hospital, Medical University of Lodz, Lodz, Poland ${ }^{2}$ Department and Clinic of Allergology, Clinical Immunology and Internal Diseases, Collegium Medicum in Bydgoszcz, Nicolaus Copernicus University in Torun, Poland

${ }^{3}$ Department of Allergology and Internal Diseases, Medical University of Bialystok, Bialystok, Poland ${ }^{4}$ Clinic of Paediatric Pneumology and Allergology, Paediatric Hospital of the Medical University of Warsaw, Warsaw, Poland ${ }^{5} \mathrm{Clinic}$ of Pneumology and Cystic Fibrosis, Regional Department of the Institute of Tuberculosis and Pulmonary Diseases, Rabka-Zdroj, Poland
\end{abstract}

Adv Dermatol Allergol 2019; XXXVI (2): 147-157

DOI: https://doi.org/10.5114/ada.2019.84591

\begin{abstract}
Severe asthma requires at least high doses of inhaled corticosteroids (ICS) in combination with a long-acting $\beta$-agonist (LABA) or systemic corticosteroids (SCS) for more than $50 \%$ of days/year to avoid loss of control, or remains uncontrolled despite the treatment described above. The diagnosis of severe asthma should be confirmed in a reference centre as it requires careful differential diagnosis and the exclusion of factors hindering the achievement of optimal control. Severe asthma represents a significant burden for the patient, their family and the healthcare system. This is due to the severity of the symptoms, drug costs, significant impairment of everyday functioning and life quality, and limitation in the professional work. In the case of ineffectiveness of the step 4 GINA treatment, the patient should be referred to a specialist centre to consider additional treatment, including anti-lgE receptor (omalizumab), anti-IL-5 receptor (mepolizumab), or an antibody directed against the $\alpha$-subunit of receptor for IL-5 (benralizumab). In the case of severe asthma, intensification of therapy should first of all include biological therapy and not the use of SCS. Biological drugs are available in Poland as a part of the therapeutic programme for the treatment of severe asthma. In practice, the therapeutic programme may change with subsequent notices of the Ministry of Health and does not have to be consistent with the Summary of Product Characteristics for individual preparations. The current review presents the basic principles of differential diagnosis of severe asthma and the selection of the optimal biological therapy in Polish conditions.
\end{abstract}

Key words: bronchial asthma, severe bronchial asthma, difficult-to-treat asthma, steroid-dependent asthma, biological treatment, omalizumab, mepolizumab, benralizumab.

\section{Definitions}

Severe asthma, in accordance with the definition included in the GINA report [1] is a form of asthma requiring therapy corresponding to step 4 or 5 (according to GINA), that is at least high-dosage inhaled corticosteroids (ICS) combined with a long-acting $\beta$ agonist (LABA) or other controller (theophylline, antileukotriene drugs); or asthma requiring the use of systemic corticosteroids (SCS) for more than $50 \%$ of days per year to prevent loss of control of the disease; or asthma that remains uncontrolled in spite of the intensive treatment described above.

The term uncontrolled asthma encompasses the forms of the disease meeting at least one of the following criteria:

- Poor control of the symptoms evaluated using commonly available questionnaires (e.g. a score higher than 1.5 in the Asthma Control Questionnaire (ACQ) or a score below 20 in the Asthma Control Test (ACT));

Address for correspondence: Maciej Kupczyk MD, PhD, Clinic of Internal Diseases, Asthma and Allergies, N. Barlicki University Clinical Hospital, Medical University of Lodz, 22 Kopcinskiego St, 90-153 Lodz, Poland, phone: +48 4267766 49, e-mail: maciej.kupczyk@umed.pl Received: 14.11.2018, accepted: 14.11.2018. 
- Frequent exacerbations of asthma (more than 2 a year, lasting at least 3 days);

- Severe exacerbations (requiring a hospitalisation and/ or use of systemic corticosteroids);

- Persistent airway obturation $\left(\mathrm{FEV}_{1} / \mathrm{FVC}\right.$ ratio $<70 \%$ or below $5^{\text {th }}$ percentile, $\mathrm{FEV}_{1}<80 \%$ in bronchial obstruction reversibility test);

- Controlled asthma deteriorating after an attempt at reducing high doses of ICS or SCS.

To summarize the above definitions, severe asthma is a form of the disease which requires intensive pharmacotherapy to be controlled or remains uncontrolled despite such a treatment. The emphasis is put on the treatment intensity, the consequences of long-term SCS therapy and the lack of disease control. Also the criteria facilitating the identification of loss of control over the disease are provided.

On the other hand, the report under the auspices of WHO [2] defines uncontrolled asthma as a form of the disease involving a risk of frequent exacerbations (or death) and/or side effects of the used medication and/or consequences of the chronic disease, including impaired respiratory function or impaired lung development in children. Three types of the disease have been identified: - Severe untreated asthma (the severe course of the disease results from the lack of access to appropriate treatment or failure to use it);

- Severe difficult-to-treat asthma, where the lack of response or poor response to therapy results from other factors than the asthma itself, such as poor patient compliance, environmental factors (e.g. tobacco smoke, household or work-related allergens), psychosocial factors and concomitant diseases;

- Severe treatment-resistant asthma, where disease control cannot be achieved in spite of using the highest doses of recommended drugs (treatment-resistant asthma, steroid-resistant asthma); or where disease control is possible only with the highest doses of drugs (e.g. steroid-dependent asthma).

In the above definitions, the emphasis is put on the fact that the difficulties in controlling asthma do not always have to result from the severe course of the asthma itself, but may be related to the symptoms of concomitant diseases, the presence of environmental factors or practical aspects (such as lack of compliance with the medical recommendations). In practice, the diagnosis of severe asthma from the perspective of indications to biological therapy requires the exclusion of the abovementioned factors hindering the achievement of the optimum disease control. This results in a practical recommendation that the patients with suspected severe asthma should be referred to a specialist consultation (of an allergologist or a pulmonologist) in a centre experienced in treating patients with severe asthma, or should be under constant supervision in such a centre. To sum up, the term 'severe asthma' covers a heteroge- neous group of patients. There are no defined pathological mechanisms or biomarkers related to this form of the disease. The diagnosis is made on the basis of the clinical image, the course of the disease and the response (or its lack) to the treatment. It should be emphasized that the functional parameters of the respiratory system (especially measured at one time point) are not an optimum way to assess the disease severity or response to the introduced biological treatment. The confirmation of the diagnosis of severe asthma should lead to consideration of indications for the inclusion of biological therapies, in accordance with the therapeutic recommendations included in the GINA guidelines [1].

\section{Epidemiology of severe asthma}

The incidence of severe asthma is estimated as $5-10 \%$ of the population of patients with bronchial asthma [1]. In reference centres specialising in the treatment of patients with severe obstructive diseases, the rate of patients with severe asthma may reach $7-15 \%$.

\section{Burdens related to severe bronchial asthma}

Severe asthma is a significant burden for the patients, their families and the healthcare system. This stems from intensified symptoms, costs of medication, a significant impairment of everyday functioning and life quality, as well as limitations in social and professional life. From the perspective of healthcare systems, the burdens are related to numerous exacerbations, hospitalisations, additional unscheduled medical consultations, and medication use. The analyses of data from Finland show that the treatment costs of a patient with severe asthma are 13 times as high as the treatment costs of patients with less severe forms of the disease [3]. In the USA, hospitalisation costs constitute as much as 51.2\% of asthma-related expenses of the state. Further 10.5\% is spent on emergency aid, $18.4 \%$ on out-patient treatment and $19.9 \%$ on drug reimbursement [4]. In Poland, the costs of out-patient treatment of exacerbations in the COAX study were estimated at PLN 247 (EUR 62.70) while the costs on an exacerbation-related hospitalisation were estimated at PLN 3,988 (EUR 1,012.00) [5]. It should be stressed that severe asthma entails significant indirect social costs, that is costs resulting from a significant prevalence and high sick absence rate, lower productivity, treatment of complications or therapy consequences (systemic corticosteroids) as well as long-term incapacity to work and premature deaths.

\section{Differential diagnosis of severe asthma}

The clinical image of uncontrolled, difficult-to-treat asthma and the suspicion of severe asthma require detailed differential diagnosis (Table 1) and the assessment of the potential factors hindering the optimum control 
over the disease (Table 2) before any treatment modification, and particularly before considering the patient eligible for biological therapy [6, 7]. In practice, the patient should be treated/supervised in a specialist centre (allergology/pulmonology) with experience in the diagnosis and treatment of patients with obstructive diseases.

\section{Therapy of severe asthma}

In accordance with the GINA guidelines, at step 5 of the treatment (in case of inefficiency of the step 4 treat-

Table 1. Differential diagnosis of bronchial asthma depending of the patient's age (based on $[6,7]$ )

\begin{tabular}{|c|c|c|}
\hline Age & Disease classification & Symptoms \\
\hline \multirow{5}{*}{$6-11$} & Foreign body & Sudden onset, local wheezing \\
\hline & $\begin{array}{l}\text { Congenital heart } \\
\text { diseases }\end{array}$ & Cardiac murmurs \\
\hline & $\begin{array}{l}\text { Bronchopulmonary } \\
\text { dysplasia }\end{array}$ & $\begin{array}{l}\text { Pre-term delivery, symptoms } \\
\text { since birth }\end{array}$ \\
\hline & Cystic fibrosis & $\begin{array}{l}\text { Cough, excessive mucous } \\
\text { production, symptoms related } \\
\text { to other organs and systems }\end{array}$ \\
\hline & Bronchiectasis & $\begin{array}{l}\text { Productive cough, recurring } \\
\text { infections }\end{array}$ \\
\hline \multirow[t]{7}{*}{$12-39$} & Sinusitis & $\begin{array}{l}\text { Mucus flowing down the } \\
\text { posterior throat wall, } \\
\text { sensation of a blocked nose, } \\
\text { symptoms of sinusitis }\end{array}$ \\
\hline & Vocal cord dysfunction & $\begin{array}{l}\text { Dyspnoea, inspiratory } \\
\text { wheezing (stridor) }\end{array}$ \\
\hline & Hyperventilation & Dizziness, paraesthesia \\
\hline & Bronchiectasis & $\begin{array}{l}\text { Productive cough, recurring } \\
\text { infections }\end{array}$ \\
\hline & $\begin{array}{l}\text { Congenital heart } \\
\text { diseases }\end{array}$ & Cardiac murmurs \\
\hline & Foreign body & Sudden onset, local wheezing \\
\hline & $\begin{array}{l}\alpha 1 \text {-antitripisin } \\
\text { deficiency }\end{array}$ & $\begin{array}{c}\text { Dyspnoea, family history, early } \\
\text { emphysema }\end{array}$ \\
\hline \multirow[t]{7}{*}{$40+$} & Vocal cord dysfunction & $\begin{array}{l}\text { Dyspnoea, inspiratory } \\
\text { wheezing (stridor) }\end{array}$ \\
\hline & COPD & $\begin{array}{l}\text { Cough, sputum, dyspnoea on } \\
\text { exertion, smoking in history }\end{array}$ \\
\hline & Bronchiectasis & $\begin{array}{l}\text { Productive cough, recurring } \\
\text { infections }\end{array}$ \\
\hline & $\begin{array}{l}\text { Circulatory } \\
\text { insufficiency }\end{array}$ & $\begin{array}{l}\text { Dyspnoea with exertion, } \\
\text { nocturnal symptoms, nocturia, } \\
\text { oedema }\end{array}$ \\
\hline & $\begin{array}{c}\text { Medication-related } \\
\text { cough (ACE inhibitors) }\end{array}$ & $\begin{array}{l}\text { Disappearance after change } \\
\text { of medication }\end{array}$ \\
\hline & Pulmonary embolism & $\begin{array}{l}\text { Sudden onset of embolism, } \\
\text { chest pain, haemoptysis }\end{array}$ \\
\hline & Obstructive sleep apnoea & Dyspnoea, sleepiness, snoring \\
\hline
\end{tabular}

ment, i.e. at least moderate or high ICS doses + LABA), the patient should be referred to a specialist centre for an assessment if they are eligible for the inclusion of additional treatment. The proposed methods of therapy intensification include the addition of tiotropium, the inclusion of anti-IgE (omalizumab) or anti-IL-5 (mepolizumab, reslizumab) biological therapy, or an antibody directed against $\alpha$ subunit of the IL-5 receptor (benralizumab). Other methods include treatment guided by induced sputum eosinophil count and bronchial thermoplasty. Adding systemic corticosteroids ( $\leq 7.5 \mathrm{mg}$ /day of prednisone, or equivalent) is considered as the last option. The sequence of recommended therapy intensification methods is clear and stems directly from the significant risk of major side effects induced by systemic corticosteroids.

\section{Burdens related to the use of systemic corticosteroids in the therapy of asthma}

The potential side effects of chronic SCS therapy include steroid diabetes, hypertension, body weight gain, skin thinning, easy bruising, oral thrush, increased infection risk, depression, myopathies, cataract, glaucoma, osteoporosis, increased risk of fractures, and insomnia. In some patients, especially after long-term or frequently repeated therapy with SCS, the clinical image resembles iatrogenic Cushing syndrome. Interestingly, the newest analysis of Waljee et al. [8] on a group of 1.5 million patients (300,000 of which received SCS at the average dose of $20 \mathrm{mg}$ of prednisone for 6 days) showed a significant increase in the risk of sepsis, venous thromboembolism and fractures even after single, relatively short courses of SCS therapy. In another observational study, chronic therapy

Table 2. Factors influencing the asthma control degree (based on [7])

\section{Concomitant diseases}

Chronic sinusitis, nose polyps, allergic rhinitis, depression, gastroesophageal reflux disease, obesity/overweight, vocal cords dysfunction

\section{Allergens and environmental factors}

Household allergens (dust mites, animal, moulds, food products), work-related allergens (isocyanates, latex, flour), cigarette smoke (active and passive exposure), environmental pollution

\section{Medication used}

Hypersensitivity to aspirin and other NSAIDs, $\beta$-blockers, ACE inhibitors

\section{Patient-dependent factors}

Proper inhalation technique, compliance, steroid phobia

\section{Psychosocial factors}

Stress, situation at home and at work, psychosocial conditions, chronic diseases 
with prednisone at the dose of $5 \mathrm{mg}$ /day was related to a significant increase in the risk of vertebral fractures (OR =9.2), myopathies $(\mathrm{OR}=3.3)$ and cataract $(\mathrm{OR}=3.1)$ [9]. To sum up, taking into consideration the risk of side effects as well as the burden for the patient and the healthcare system related to the use of SCS, therapy intensification for severe asthma should first involve inclusion of biological therapy and not the use of SCS. When SCS are used for $\geq 3$ months, osteoporosis prophylaxis is recommended.

\section{Clinical trials on using biological therapies in the treatment of severe asthma}

The results of many randomised, placebo-controlled trials confirmed the efficiency of omalizumab in the improvement of disease control and patient life quality. The observed results included a decrease in the use of relievers, ICS and SCS, as well as a significant drop in the risk of exacerbations in the group of patients with severe atopic asthma. For this reason, omalizumab entered the therapy standards for the step 5 bronchial asthma therapy according to the GINA guidelines [1]. The registration trials of mepolizumab, a humanised monoclonal anti-IL-5 antibody, are known under the acronyms DREAM, SIRIUS and MENSA. Pavord et al. [10] described the results of the observation of a group of 621 patients (aged 17-74 years) with uncontrolled severe asthma, frequent exacerbations and sputum eosinophilia (> 3\%), blood eosinophilia (> 300 cells $/ \mu l$ ) or fractional exhale nitric oxide (FeNO) > 50 ppb. The number of exacerbations dropped by $39 \%$ to $48 \%$, depending on the mepolizumab dose $(75,250$ and $750 \mathrm{mg}$ i.v. for a year) in the active group in comparison to the placebo group. Bel et al. [11] assessed whether it is possible to reduce the doses of SCS after introducing $100 \mathrm{mg}$ of mepolizumab subcutaneously in patients with severe asthma and blood eosinophilia over 150 cells/ $\mu \mathrm{l}$ at screening or over 300 cells/ $\mu$ in the previous 12 months. In the group receiving the active substance, it was possible to reduce the doses of oral corticosteroids by $50 \%$, and achieve a simultaneous 32\% drop in the number of exacerbations and a significant improvement of the disease control in comparison to placebo. In the MENSA trial, Ortega et al. [12] observed a cohort of 576 patients with severe asthma (aged 12-82 years), with frequent exacerbations and eosinophilia-related criteria as in the previously described study. The patients received mepolizumab: $100 \mathrm{mg}$ subcutaneously or 75 mg intravenously. The results included a significant drop in the number of exacerbations (53\% after subcutaneous administration and $47 \%$ after intravenous administration) as well as an improvement of the airflow parameters, disease control and life quality. Two key clinical trials on the use of benralizumab in severe asthma are known under the acronyms CALIMA [13] and SIROCCO [14]. The CALIMA study [13] involved 2,505 patients (aged $12-75$ years) with severe asthma which could not be controlled despite using moderate or high doses of inhaled corticosteroids (ICS) together with long-acting $\beta$-antagonist (LABA), who had at least two exacerbations in the previous year. The patients were randomised $(1: 1: 1)$ to groups receiving benralizumab $30 \mathrm{mg}$ SC every 4 weeks (Q4W), benralizumab $30 \mathrm{mg}$ SC every 8 weeks (Q8W, first three doses every 4 weeks) or placebo for 56 weeks. Benralizumab significantly decreased the frequency of asthma exacerbations (by about 36\% in the Q4W scheme and by 28\% in the Q8W scheme) in comparison to placebo. In the CALIMA study [13], benralizumab significantly decreased the frequency of asthma exacerbations (by $45 \%$ in the Q4W scheme and by $51 \%$ in the Q8W scheme) in comparison to placebo. The groups receiving benralizumab had also better ventilation parameters, and in the Q8W group the intensity of the symptoms decreased. Nair et al. (ZONDA study) [15] evaluated the potential influence of benralizumab on the reduction of the ICS dose in patients with severe asthma. Two hundred and twenty patients were randomised to active treatment (benralizumab 30 mg SC every 4 or 8 weeks, three first doses every 4 weeks) or placebo groups. The follow-up in week 28 showed a significant reduction in the average dose of oral corticosteroids in patients treated with benralizumab (a decrease by $75 \%$ in comparison to baseline in the active treatment group, compared to $25 \%$ in the placebo group, $p<0.001)$. The frequency of exacerbations was 55\% lower (in comparison to placebo) in the Q4W scheme and 70\% lower (in comparison to placebo) in the Q8W scheme. The key characteristics of benralizumab in comparison to other anti-IL-5 monoclonal antibodies (mepolizumab and reslizumab) are presented in Table 3.

In most clinical trials and real-life observations, the number and character of side effects did not differ between the biological therapy and placebo groups. The observation of pregnancies and health of the children from 169 pregnancies during which the mothers received omalizumab (exposure median: 8.8 months) did not show an increased risk of birth defects or complications during pregnancy and delivery [16]. The question how the therapies influence the risk of parasitic infestations is still to be investigated. However, there are no reports suggesting a significant increase in the infestation risk in our climate zone. There are no detailed data about the risk of potential systemic hypersensitivity reactions in patients with asthma receiving biological therapy. It is recommended that after the administration of biological drugs the patient should remain under the supervision of healthcare professionals trained in the diagnosis and treatment of anaphylactic reactions for $2 \mathrm{~h}$ after the first dose of the drug and for 30 min after every subsequent dose.

\section{Real-life studies on using biological therapies in the treatment of severe asthma}

After the launch of omalizumab on the market, reallife studies evaluating its efficiency in the conditions of 
Table 3. Comparison of benralizumab and other antibodies influencing the interleukin 5 signalling pathway

\begin{tabular}{|c|c|c|c|}
\hline $\begin{array}{l}\text { Monoclonal } \\
\text { antibody }\end{array}$ & Mechanism of action & Dosage & Clinical effects \\
\hline Benralizumab & $\begin{array}{l}\text { An IgGlk class humanised } \\
\text { monoclonal antibody binding } \\
\text { to the IL-5 receptor } \alpha \text {-chain, } \\
\text { inducing the processes of } \\
\text { antibody-dependent cellular } \\
\text { cytotoxicity and leading to the } \\
\text { depletion of tissue eosinophils }\end{array}$ & $\begin{array}{l}30 \text { mg subcutaneously } \\
\text { every } 8 \text { weeks (first } \\
3 \text { doses every } \\
4 \text { weeks) }\end{array}$ & $\begin{array}{l}\text { Decrease in the level of eosinophils and basophils in } \\
\text { blood to the detection level, reduction of eosinophil } \\
\text { precursors in the bone marrow by } 80 \% \text {, significant } \\
\text { reduction in the number of exacerbations in patients } \\
\text { with severe asthma, decrease in the dose of systemic } \\
\text { corticosteroids, a good safety profile, approved by } \\
\text { the FDA and EMA }\end{array}$ \\
\hline Mepolizumab & $\begin{array}{l}\text { An IgG1/א class humanised } \\
\text { monoclonal antibody with high } \\
\text { affinity and specificity for IL-5 }\end{array}$ & $\begin{array}{l}100 \mathrm{mg} \\
\text { subcutaneously every } \\
4 \text { weeks }\end{array}$ & $\begin{array}{l}\text { The first anti-IL-5 antibody. Numerous clinical trials } \\
\text { have shown its safety and efficiency in the therapy } \\
\text { of severe eosinophilic asthma. It significantly reduces } \\
\text { the number of exacerbations and the dose of systemic } \\
\text { corticosteroids. It has a good safety profile and has } \\
\text { been approved by the FDA and EMA }\end{array}$ \\
\hline Reslizumab & $\begin{array}{l}\text { An IgG } 4 / \kappa \text { class humanised } \\
\text { monoclonal antibody with high } \\
\text { affinity and specificity for IL-5 }\end{array}$ & $\begin{array}{c}3 \mathrm{mg} / \mathrm{kg} \text { bw } \\
\text { intravenously every } \\
4 \text { weeks }\end{array}$ & $\begin{array}{l}\text { Wide safety and efficiency data, approval by the } \\
\text { FDA and EMA. Intravenous route of administration } \\
\text { may be a practical limitation in comparison to other } \\
\text { antibodies from this group }\end{array}$ \\
\hline
\end{tabular}

everyday clinical practice were conducted. Korn et al. [17] concluded that as early as after 6 months of using this antibody in patients with severe asthma, the number of patients with exacerbations decreased almost five times, and the total number of exacerbations decreased by $82 \%$. Braustahl et al. published the results of the expeRience register, the main aim of which was to assess the influence of omalizumab therapy on healthcare system resources. In a group of 943 patients with uncontrolled atopic asthma, the use of omalizumab led to an increase in the number of patients without exacerbations from $6.8 \%$ to $54.1 \%$ and $67.3 \%$ in month 12 and 24 , respectively. The intensity of the symptoms and the use of reliever drugs dropped by over $50 \%$. Also the use of systemic corticosteroids decreased significantly [18]. The number of hospitalisations, visits to emergency rooms and unplanned medical consultations after 24 months dropped 7, 18 and 9.5 times, respectively. Similar experiences from Poland, from the centre in Lodz, indicate that a good or very good response is observed in over $80 \%$ of patients as early as in the $16^{\text {th }}$ week of treatment. The number of exacerbations falls visibly in almost all patients, and an improvement of the disease control (ACQ score decreasing from 3.23 to 2.23) and patient quality life (AQLQ score increasing from 3.43 to 4.24$)$ is observed [19].

\section{Characteristics of biological therapies of asthma in Polish conditions}

In Poland, biological drugs are available to patients with asthma as part of the therapeutic programme for severe asthma (Tables 4 and 5). In practice, the rules of the therapeutic programme do not have to comply with the information provided in the Summary of Product Characteristics (SmPC) for a given drug (Tables 6 and 7) [20].
As far as the omalizumab therapy programme is concerned, the next steps that should be taken are decreasing the eligibility age and increasing the spirometric criterion in accordance with the SmPC. Pursuant to Art. 15 of the Act of 27 August 2004 on publicly funded healthcare benefits, the healthcare benefits belonging to drug prescription programmes belong to guaranteed publicly funded benefits. Pursuant to Art. 6 of the Act on the reimbursement of medicines, foodstuffs intended for particular nutritional use and medical devices, the drugs used in drug prescription programmes constitute a separate reimbursement category and are given to programme participants free of charge. Currently, the drug prescription programme for severe allergic asthma is carried out in 44 centres in Poland which have executed appropriate agreements with the Polish National Health Fund. Biological therapies are administered in the out-patient scheme or during one-day hospitalisations. The patient must be considered eligible for the programme by an allergologist or pulmonologist working in one of the centres contracted for this benefit, in accordance with the criteria specified in the Notice of the Ministry of Health on the reimbursement of medicines, foodstuffs intended for particular nutritional uses and medical devices. In accordance with the current programme regulations, the efficiency of the biological therapy is evaluated in Week 16 (oma) or 24 (mepo), 52 and 104, and then after every 52 treatment weeks from the previous decision about the therapy continuation. The evaluation is based on the disease control, life quality, spirometry results, use of drugs (including SCS), number of exacerbations and response to therapy measured in the GETE scale.

The availability of biological therapies may be limited for practical and logistics reasons (transport, eligibility for therapy, care in the centres participating in the drug pre- 
Table 4. Inclusion criteria and contraindications of omalizumab therapy according to the treatment programme for uncontrolled IgE-dependent asthma (Notice of the Ministry of Health applicable from 1 March 2018 (based on [20)). Note: the criteria may change in the subsequent notices of the ministry and are not identical with the registered indications for omalizumab

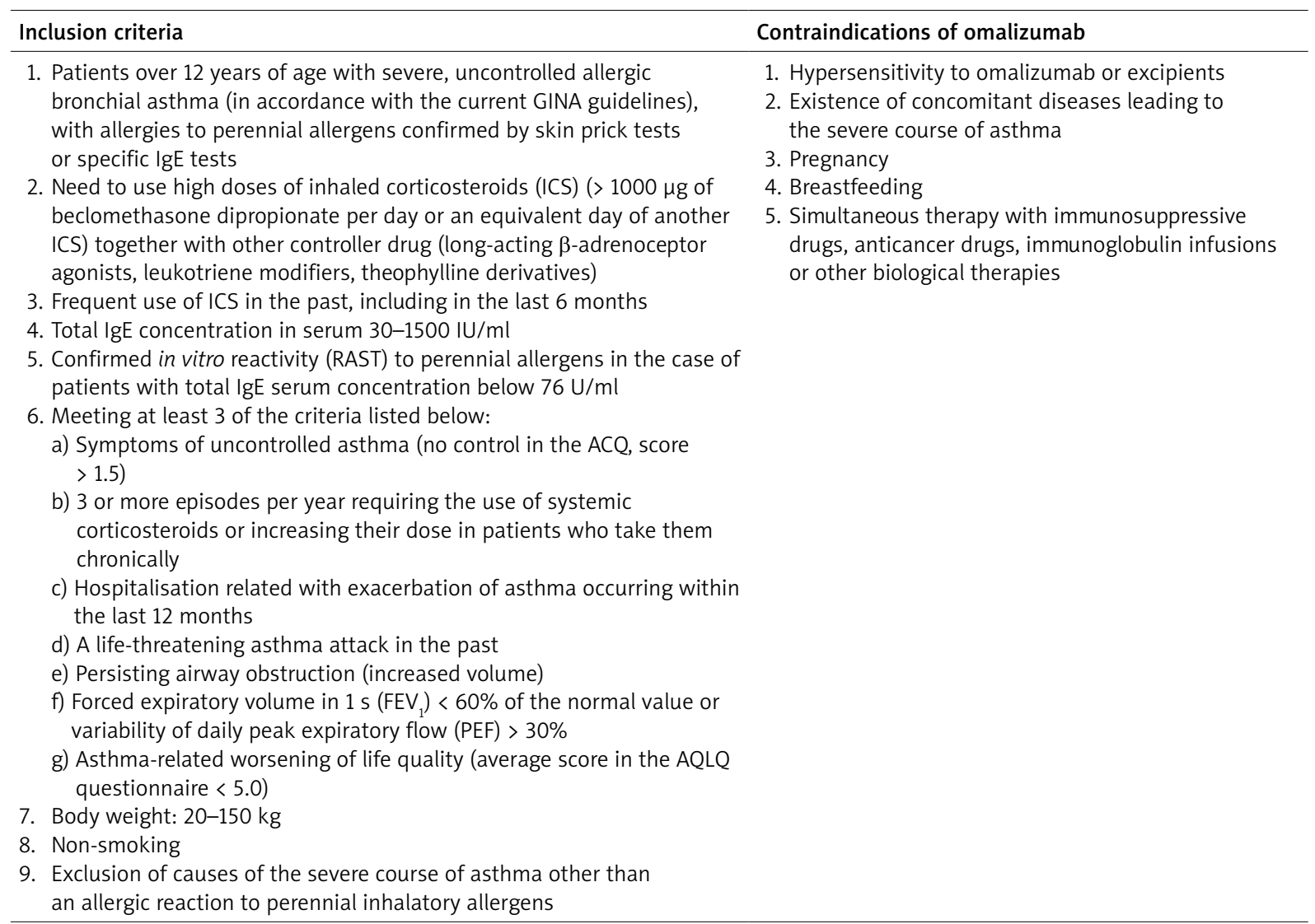

Table 5. Inclusion criteria and contraindications of mepolizumab therapy according to the treatment programme for uncontrolled IgE-dependent asthma (Notice of the Ministry of Health applicable from 1 March 2018 (based on [20])). Note: the criteria may change in the subsequent notices of the ministry and are not identical with the registered indications for mepolizumab

\begin{tabular}{|c|c|}
\hline Inclusion criteria & Contraindications of mepolizumab \\
\hline $\begin{array}{l}\text { 1. Patients over } 18 \text { years of age with severe, eosinophilic asthma resistant } \\
\text { to treatment, diagnosed on the basis of the number of eosinophils } \\
\text { in blood over } 350 / \mu \text { l on the eligibility visit or within } 12 \text { months before } \\
\text { the programme eligibility assessment } \\
\text { 2. Need to use high doses of inhaled corticosteroids (ICS) (> } 1000 \mu g \\
\text { of beclomethasone dipropionate per day or an equivalent dose } \\
\text { of another ICS) together with other controller drug (long-acting } \\
\beta \text {-adrenoceptor agonists, leukotriene modifiers, theophylline derivatives, } \\
\text { long acting muscarinic antagonists) } \\
\text { 3. Previous year: two or more exacerbations requiring the use of systemic } \\
\text { corticosteroids or increasing their dose for a period longer than } 3 \text { days } \\
\text { in the patients who use them chronically, regardless of whether they } \\
\text { required a hospitalisation or a visit in the emergency room } \\
\text { 4. Forced expiratory volume in } 1 \mathrm{~s} \text { (FEV } \text { ) }_{1} 80 \% \text { of the normal value before } \\
\text { the administration of a bronchodilator during the eligibility visit } \\
\text { 5. Symptoms of uncontrolled asthma (no control in the ACQ, score > 1.5), } \\
\text { and asthma-related worsening of life quality (average score in the AQLQ } \\
\text { questionnaire }<\text { 5.0) in spite of the treatment } \\
\text { 6. Exclusion of other hypereosinophilic syndromes } \\
\text { 7. Patient's declaration that he/she is a non-smoker } \\
\text { 8. Exclusion of parasitic infestations on the basis of the normal result } \\
\text { of the faecal test } \\
\text { 9. Exclusion of other clinically relevant pulmonary diseases }\end{array}$ & $\begin{array}{l}\text { 1. Hypersensitivity to mepolizumab or excipients } \\
\text { 2. Pregnancy } \\
\text { 3. Breastfeeding } \\
\text { 4. Simultaneous therapy with immunosuppressive } \\
\text { drugs, anticancer drugs, immunoglobulin infusions } \\
\text { or other biological therapies } \\
\text { 5. Taking other biological therapies for asthma } \\
\text { (e.g. omalizumab): for } 6 \text { months after the } \\
\text { discontinuation of that therapy }\end{array}$ \\
\hline
\end{tabular}


Table 6. Differences between the therapeutic programme criteria and the Summary of Product Characteristics of omalizumab (based on [20])

\begin{tabular}{|c|c|c|}
\hline Parameter & Programme & SmPC \\
\hline Age & $\geq 12$ years old & $\geq 6$ years old \\
\hline clgE & $30-1500 \mathrm{lU} / \mathrm{ml}$ & $30-1500 \mathrm{IU} / \mathrm{ml}$ \\
\hline $\begin{array}{l}\text { Severe allergic asthma with an allergy } \\
\text { to perennial allergens }\end{array}$ & Yes & Yes \\
\hline $\begin{array}{l}\text { Asthma which remains uncontrolled in spite of } \\
\text { high doses of ICS and an add-on controller drug }\end{array}$ & $\begin{array}{c}\text { ACQ > } 1.5(1 / 6)^{\star} \\
>1000 \mu \mathrm{g} \text { BDP-CFC/d } \\
+ \text { LABA or LTRA or theophylline }\end{array}$ & $\begin{array}{c}\text { Symptomatic } \\
\text { High doses of ICS + LABA }\end{array}$ \\
\hline SCS used permanently or in pulses & Yes & No \\
\hline Multiple exacerbations & $\geq 3 /$ year $(1 / 6)^{*}$ & $\begin{array}{l}\text { Yes (without specifying } \\
\text { the number) }\end{array}$ \\
\hline Hospitalisations due to asthma exacerbations & Yes $(1 / 6)^{\star}$ & Not required \\
\hline Life-threatening attack in medical history & Yes $(1 / 6)^{\star}$ & Not required \\
\hline Ventilation disorders & $\mathrm{FEV}_{1}<60 \%$ of the normal value $(1 / 6)^{*}$ & $\mathrm{FEV}_{1}<80 \%$ of the normal value \\
\hline Additional criteria & AQLQ score $<5.0(1 / 6)^{\star}$ & Not mentioned \\
\hline Contraindications & Hypersensitivity to the drug & Hypersensitivity to the drug \\
\hline Other diseases causing a severe course of asthma & Yes & Not mentioned \\
\hline Tobacco & Non-smoking (obligatory condition) & Not mentioned \\
\hline Pregnancy & An absolute contraindication & $\begin{array}{c}\text { Admissible, if benefits outweigh } \\
\text { the risk }\end{array}$ \\
\hline $\begin{array}{l}\text { Contraindication: simultaneous therapy with } \\
\text { immunosuppressive drugs, anticancer drugs, } \\
\text { immunoglobulin infusions or other biological } \\
\text { therapies }\end{array}$ & Yes & No studies \\
\hline Therapy duration & $\begin{array}{l}\text { After } 24 \text { months, omalizumab therapy must be } \\
\text { suspended for at least } 6 \text { months. In the case } \\
\text { of a significant worsening of disease control, } \\
\text { the therapy may be reinitiated }\end{array}$ & No limit \\
\hline
\end{tabular}

scription programme). Currently, several dozen participating centres administer omalizumab to over 450 patients. The average number of patients receiving this drug in Poland is approximately $11 / 1$ million inhabitants, and is almost the lowest in the whole European Union. The drug has been available on the market for over 10 years, with abundant clinical experience and many reports confirming its efficiency in everyday clinical practice and not only randomized clinical trials. There are also extensive databases confirming a good safety profile of this antibody. Since 1 November 2017, mepolizumab has become reimbursed within the drug prescription programme: "Treatment of severe, IgE-dependent allergic asthma (ICD-10 J45.0) and severe eosinophilic asthma (ICD-10 J 45)". The works on the regulations of a therapeutic programme involving benralizumab and its introduction in Poland are in progress.

\section{Selection of therapy for patients with diagnosed severe asthma}

Thanks to the better understanding of the mechanisms responsible for the development of asthma and its uncontrolled course, as well as the advancement of medicine, recently there have appeared new methods of treatment for this group of patients which have been appreciated by the GINA experts. In the GINA 2018 report, the experts recommend the following approach for the step 5 treatment before the initiation of systemic corticosteroids:

- in patients $\geq 12$ years of age with exacerbations in medical history (regardless of the disease phenotype): introduction of tiotropium;

- for an endotype with dominating type 2 airway inflammation:

- in allergic asthma: omalizumab (anti-lgE),

- in eosinophilic asthma: mepolizumab or reslizumab or benralizumab (anti-IL-5).

The first step in the assessment of the disease phenotype is the evaluation whether its dominating pathomechanism is type 2 airway inflammation. Indirect markers of this type of inflammation include peripheral blood eosinophilia $\geq 150$ cells/ $\mu$ l, FeNO $>20$ ppb, sputum $(\geq 2 \%)$, and a significant role of allergies in the clinical picture of the disease. There are no studies which would 
Table 7. Differences between the therapeutic programme criteria and the Summary of Product Characteristics of mepolizumab (based on [20])

\begin{tabular}{|c|c|c|}
\hline Parameter & Programme & SmPC \\
\hline Age & $>18$ years old & $>18$ years old \\
\hline Severe eosinophilic asthma & Yes, 350 cells/ $\mu \mathrm{l}$ & Yes \\
\hline $\begin{array}{l}\text { Asthma which remains uncontrolled in spite of high } \\
\text { doses of ICS and an additional controlling drug }\end{array}$ & $\begin{array}{c}\text { ACQ }>1.5 \\
>1000 \mu g \text { BDP-CFC/d } \\
+ \text { LABA or LTRA or Theo or LAMA }\end{array}$ & $\begin{array}{c}\text { Symptomatic } \\
\text { High doses } \\
+ \text { LABA or LTRA or Theo or LAMA }\end{array}$ \\
\hline $\begin{array}{l}\text { Need to use SCS permanently or in case of } \\
\text { exacerbations }\end{array}$ & Yes, at least during the exacerbations & $\begin{array}{l}\text { Yes, at least during the } \\
\text { exacerbations (clinical trials) }\end{array}$ \\
\hline Multiple exacerbations & $\geq 2 /$ year & Yes \\
\hline Ventilation disorders & $\mathrm{FEV}_{1}<80 \%$ of the normal value & In 2 clinical trials \\
\hline Additional criteria & AQLQ $<5.0$ points & Not mentioned \\
\hline Contraindications & Hypersensitivity to the drug & Hypersensitivity to the drug \\
\hline Other diseases causing a severe course of the asthma & Yes & Not mentioned \\
\hline Tobacco & Non-smoking (obligatory condition) & Not mentioned \\
\hline Pregnancy & An absolute contraindication & $\begin{array}{c}\text { Admissible, if benefits outweigh } \\
\text { the risk }\end{array}$ \\
\hline $\begin{array}{l}\text { Contraindication: simultaneous therapy with } \\
\text { immunosuppressive drugs, anticancer drugs, } \\
\text { immunoglobulin infusions or other biological } \\
\text { therapies }\end{array}$ & Yes & $\begin{array}{l}\text { No studies, low probability } \\
\text { of interaction }\end{array}$ \\
\hline Therapy duration & $\begin{array}{c}\text { After } 24 \text { months, mepolizumab therapy } \\
\text { must be suspended for at least } 6 \\
\text { months. In the case of a significant } \\
\text { worsening of disease control, the } \\
\text { therapy may be reinitiated }\end{array}$ & No limit \\
\hline
\end{tabular}

clearly define the phenotype of patients with the best response to a given type of biological therapy. In the case of omalizumab, there are a few studies proving the efficiency of this antibody in non-allergic asthma [21] and asthma concomitant to chronic rhinosinusitis with nasal polyps [22]. Similarly, mepolizumab was found to be effective for atopic and non-atopic asthma, steroiddependent and steroid-independent asthma, and the key biomarkers of therapy efficiency include peripheral blood eosinophilia, bronchial obturation reversibility and body weight. Biological therapies are an interesting alternative in the case of severe asthma with concomitant chronic sinusitis, nasal polyps and hypersensitivity to aspirin and other NSAIDs [23]. Further real-life studies facilitating the optimum selection of biological therapy are necessary. Figure 1 presents a proposal of an algorithm for the allocation of patients suffering from severe asthma to biological therapies, taking into consideration the criteria of the therapeutic programme (based on [24]). Similarly, the therapy duration is still an open question. The current programme guidelines recommend suspending biological therapy after 24 months of successful therapy, and follow-up (visits every 4-6 weeks) for a period of at least 6 months with the assessment of the disease control.
In the case of worsening, the drug may be reintroduced. The patient may be considered eligible for a biological therapy, if they meet all the inclusion criteria and do not meet any of the programme exclusion criteria. Kupryś et al. [19] described a group of 11 patients who after the introduction of omalizumab presented a good response to treatment, with the drop of the average SCS dose from $22.73 \mathrm{mg}$ to $3.86 \mathrm{mg}$ of prednisone. After the discontinuation of therapy with omalizumab, it was observed that the disease control gradually decreased, the use of systemic steroids increased to $33.33 \mathrm{mg} /$ day and the number of exacerbations increased from 1.6 per year during the therapy to 5.2 per year. Nine out of eleven patients had serious exacerbations within first 5 months after the end of the omalizumab therapy. Taking into consideration the results of the clinical observations, it can be concluded that biological therapy duration should depend on the severity and duration of asthma.

\section{Pharmacoeconomics of biological therapies in severe asthma}

The description of direct and indirect costs in severe asthma was presented above. The introduction of 


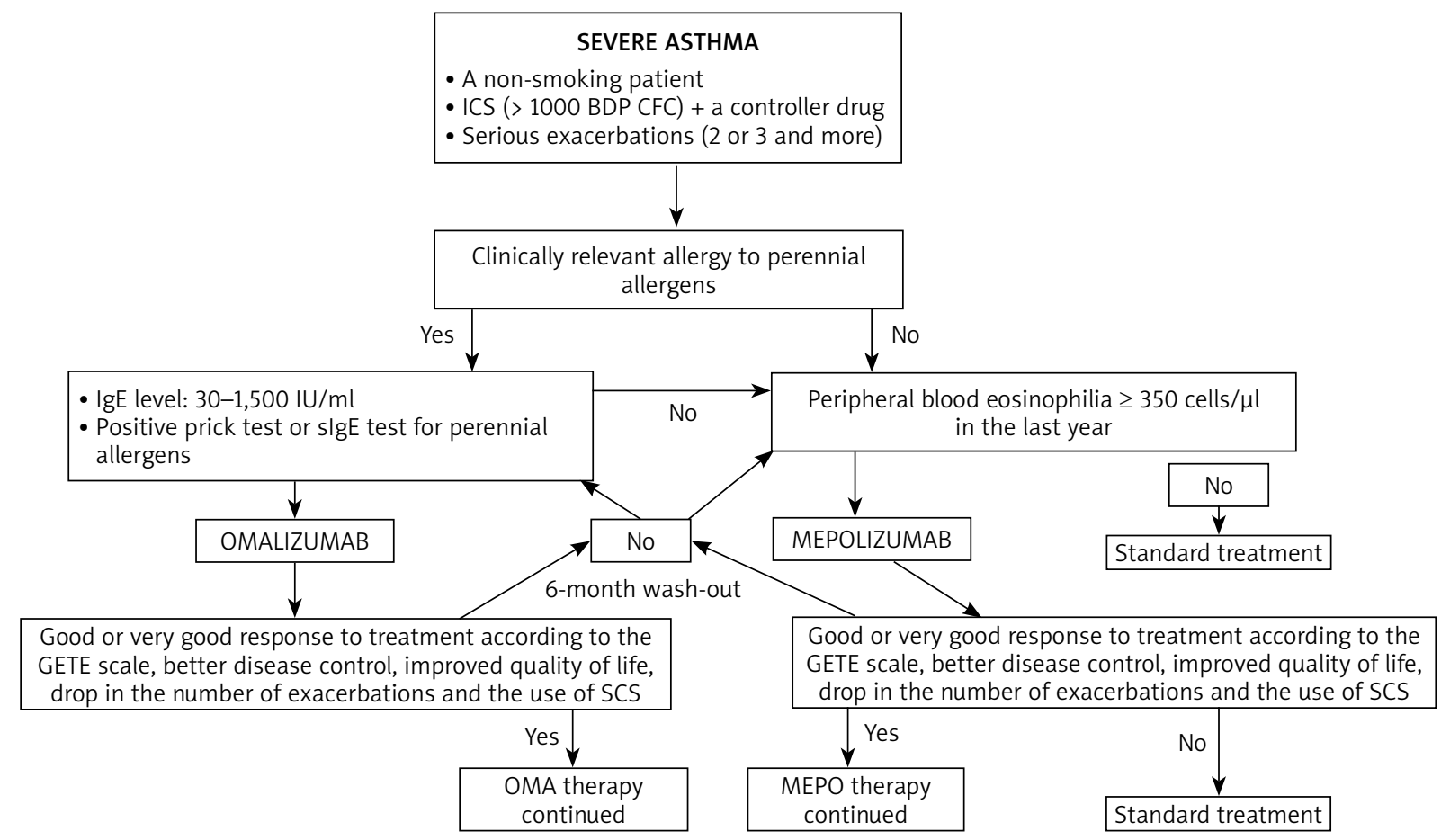

Figure 1. A proposal of an algorithm for the allocation of patients suffering from severe asthma to biological therapies, taking into consideration the criteria of the therapy programme in Poland (based on [24])

biological therapy in medically justified cases of severe disease forms leads to a decreased demand for healthcare system resources, which results particularly from the reduction in the number of exacerbations, hospitalisations, unscheduled medical consultations and emergency services, proved both in clinical trials and real-life observations. The savings related to the reduction in indirect costs, improvement of life quality, reduction in the number of sick absences and better productivity at school and work should not be underestimated. However, these aspects are difficult to appraise in pharmacoeconomic analyses. The results of the analysis of the cost-efficiency of omalizumab therapy in Spain showed that the cost of therapy resulting in preventing one exacerbation is approx. EUR 1,131 per year, and the cost of a 3-point improvement in the ACT scale is EUR 4,125. In the comparison of standard therapy, biological therapy (omalizumab) and thermoplasty in the USA, the cost for omalizumab compared to standard therapy was estimated for USD 552/QALY (Quality-Adjusted Life Year) [5]. The analysis of contracts for hospital treatment within the drug prescription programme (omalizumab therapy) in 2014 in Poland showed that the National Health Fund (NFZ) executed programme-related contracts with 36 healthcare providers for a total sum of PLN 15.23 million. When divided by the number of inhabitants of a given province (value per capita), this gives PLN 0.40 per insured person.

\section{Conclusions and practical recommendations}

According to estimations, in Poland there are over 1,000 patients with severe uncontrolled allergic asthma, but only about 500 are treated within the severe asthma treatment programme. Therefore, not all patients who could benefit from this therapy receive biological treatment.

- Severe asthma is a form of asthma which requires at least high doses of ICS in combination with a LABA or SCS for more than $50 \%$ of days/year to avoid loss of control, or asthma, which remains uncontrolled despite the treatment described above.

- The disease control is defined on the basis on the control of the symptoms (ACQ, ACT questionnaires), the number of exacerbations and the results of spirometry.

- Severe/uncontrolled asthma is also a form of the disease in which the disease control is deteriorating after any attempt at reducing high doses of inhaled corticosteroids or SCS.

- The difficulties in controlling asthma do not always have to result from the severe course of the asthma itself, but may be related to the symptoms of concomitant diseases, presence of environmental factors or practical aspects (such as lack of compliance).

- The diagnosis of asthma requires the exclusion of factors hindering the optimum control of the disease. 
- The suspicion of severe asthma requires in-depth differential diagnosis.

- Patients with a suspected severe form of the disease should be referred to a specialist consultation (of an allergologist or a pulmonologist) in a centre experienced in the treatment of patients with severe asthma or should be under constant supervision in such a centre.

- The incidence of severe asthma is estimated at 5-10\% of the population of patients with bronchial asthma.

- Severe asthma is a significant burden for the patients, their families and the healthcare system. This stems from intensified symptoms, costs of the medication, a significant impairment of everyday functioning and life quality as well as limitations in the social and professional life. From the perspective of healthcare systems, the burdens are related to numerous exacerbations, hospitalisations, additional unscheduled medical consultations, and medication use.

- In the case of ineffectiveness of the step 4 GINA treatment (at least moderate/high doses of ICS + LABA), the patient should be referred to a specialist centre to consider the additional treatment.

- Therapy intensification methods in severe asthma include introducing tiotropium, introducing anti-lgE (omalizumab) or anti-IL-5 (mepolizumab, reslizumab) biological therapy, or an antibody directed against $\alpha$ subunit of the IL-5 receptor (benralizumab), treatment guided by the induced sputum eosinophil count and bronchial thermoplasty.

- Taking into consideration the burden for the patient and the healthcare system related to the use of SCS, therapy intensification for severe asthma should first involve the biological therapy and not the use of SCS.

- When SCS are used for $\geq 3$ months, osteoporosis prophylaxis is recommended.

- The results of many randomised, placebo-controlled trials confirmed the efficiency of biological drugs in the improvement of disease control and patient life quality. The observed results included a decrease in the use of relievers, ICS and SCS, as well as a significant drop in the risk of exacerbations in the group of patients with severe asthma.

- Real-life studies confirmed the efficiency of biological therapy in severe asthma in the everyday clinical practice.

- In Poland, biological therapies are available to patients with asthma as part of the therapeutic programme for severe asthma.

- In practice, the criteria of the therapeutic programme may change in the subsequent notices of the Ministry of Health and do not have to be identical with the assumptions of the SmPCs of the particular drugs.

- The availability of biological therapies may be limited for practical and logistics reasons (transport, eligibility for therapy, care in the centres participating in the drug prescription programme).
- The patient must be considered eligible for the programme by an allergologist or pulmonologist working in one of the centres with the contract for this benefit, in accordance with the criteria specified in the notice of the Ministry of Health on the reimbursement of medicines.

- Current programme guidelines recommend suspending biological therapy after 24 months of successful therapy, and follow-up (visits every 4-6 weeks) for a period of at least 6 months with the assessment of the disease control. In the case of worsening, the drug may be reintroduced.

- The experts recommend the following approach for the step 5 treatment before the initiation of systemic corticosteroids: introduction of tiotropium regardless of the disease phenotype in patients $\geq 12$ years of age with exacerbations in medical history; phenotype-dependent treatment: omalizumab (anti-lgE) for allergic asthma; mepolizumab or reslizumab or benralizumab (anti-IL5) for eosinophilic asthma.

- There are no biomarkers or studies which would clearly define the phenotype of patients with the best response to a given type of biological therapy.

\section{Conflict of interest}

The authors declare no conflict of interest.

\section{References}

1. Global Strategy for Asthma Management and Prevention GINA - Revised 2018 Available at: www.ginasthma.org

2. Bousquet J, Mantzouranis E, Cruz AA, et al. Uniform definition of asthma severity, control, and exacerbations: document presented for the World Health Organization Consultation on Severe Asthma. J Allergy Clin Immunol 2010; 126: 926-38.

3. Haahtela T, Laitinen LA. Asthma Programme in Finland 19942004. Report of a Working Group. Clin Exp Allergy 1996; 26 (Suppl 1): 1-24.

4. Lozano P, Sullivan SD, Smith HD, et al. The economic burden of asthma in US children: estimates from the National Medical Expenditure Survey. J Allergy Clin Immunol 1999; 104: 957-63.

5. Jahnz-Różyk K. Farmakoekonomika astmy. In: Astma ciężka i trudna. Jahnz-Różyk K (ed.). Wydawnictwo Promedicina, Warsaw 2016; 277-88.

6. Bodzenta-Lukaszyk A, Fal AM, Jassem E, et al. The statement of the Polish Society of Allergology experts on the treatment of difficult-to-treat asthma. Pneumonol Alergol Pol 2015; 83: 324-34.

7. Fal AM. Współchorobowości astmy ciężkiej. Astma ciężka. In: Monografie chorób płuc. Kupczyk M, Piotrowski W (eds). ViaMedica, Gdańsk 2016; 58.

8. Waljee AK, Rogers MAM, Lin P, et al. Short term use of oral corticosteroids and related harms among adults in the United States: population based cohort study. BMJ 2017; 357: j1415. 
9. Walsh LJ, Wong CA, Oborne J, et al. Adverse effects of oral corticosteroids in relation to dose in patients with lung disease. Thorax 2001; 56: 279-84.

10. Pavord ID, Korn S, Howarth P, et al. Mepolizumab for severe eosinophilic asthma (DREAM): a multicenter, double-blind, placebo-controlled trial. Lancet 2012; 380: 651-9.

11. Bel EH, Wenzel SE, Thompson PJ, et al. Oral glucocorticoidsparing effect of mepolizumab in eosinophilic asthma. N Engl J Med 2014; 371: 1189-97.

12. Ortega HG, Liu MC, Pavord ID, et al. Mepolizumab treatment in patients with severe eosinophilic asthma. N Engl J Med 2014; 37: 1198-207.

13. FitzGerald JM, Bleecker ER, Nair P, et al. Benralizumab, an anti-interleukin-5 receptor $\alpha$ monoclonal antibody, as addon treatment for patients with severe, uncontrolled, eosinophilic asthma (CALIMA): a randomised, double-blind, placebo-controlled phase 3 trial. Lancet 2016; 388: 2128-41.

14. Bleecker ER, FitxGerald JM, Chanez P, et al. Efficacy and safety of benralizumab for patients with severe asthma uncontrolled with high-dosage inhaled corticosteroids and long-acting beta2-agonists (SIROCCO): a randomised, multicentre, placebo-controlled phase 3 trial. Lancet 2016; 388: 2115-27.

15. Nair P, Wenzel S, Rabe KF, et al. Oral glucocorticoid-sparing effect of benralizumab in severe asthma. N Engl J Med 2017; 376: 2448-58.

16. Namazy J, Cabana MD, Scheuerle AE, et al. The Xolair Pregnancy Registry (EXPECT): the safety of omalizumab use during pregnancy. J Allergy Clin Immunol 2015; 135: 407-12.

17. Korn S, Thielen A, Seyfired S, et al. Omalizumab in patients with severe persistent allergic asthma in a real-life setting in Germany. Respir Med 2009; 103: 1725-31.

18. Braustahl GJ, Chen CW, Maykut R, et al. The expeRience registry: the "real-world" effectiveness of omalizumab in allergic asthma. Respir Med 2013; 107: 1141-51.

19. Kuprys-Lipińska I, Kuna P. Loss of asthma control after cessation of omalizumab treatment: real life data. Adv Dermatol Allergol 2014; 31: 1-5.

20. Kupryś-Lipińska I, Molińska J, Kupczyk M, et al. Możliwości leczenia ciężkiej niekontrolowanej astmy w Polsce. Terapia 2018, 4: 55-61.

21. Garcia G, Magnan A, Chiron R, et al. A proof-of-concept randomized, controlled trial of omalizumab in patients with severe, difficult-to-control nonatopic asthma. Chest 2013; 144: 411-9.

22. Gevaert P, Calus L, Van Zele T, et al. Omalizumab is effective in allergic and nonallergic patients with nasal polyps and asthma. J Allergy Clin Immunol 2013; 131: 110-6.

23. Kowalski M, Agache I, Bavbek S, et al. Diagnosis and management of NSAID-Exacerbated Respiratory Disease (NERD) - a EAACI position paper. Allergy 2019; 74: 28-39.

24. Kupryś-Lipińska I, Kupczyk M, Łacwik P, et al. Algorytm opieki lekarskiej nad chorym na ciężką niekontrolowaną astmę oskrzelową w kontekście funkcjonowania w Polsce programów lekowych z terapią biologiczną. Terapia 2018; 9: 1-9. 